\title{
Пространственное перераспределение излучения во флип-чип фотодиодах на основе двойных гетероструктур InAsSbP/InAs
}

\author{
(С) А.Л. Закгейм ${ }^{1}$, Н.Д. Ильинская ${ }^{2}$, С.А. Карандашев ${ }^{2}$, А.А. Лавров ${ }^{3}$, Б.А. Матвеев ${ }^{2}$, \\ M.A. Ременный ${ }^{2}$, Н.М. Стусь ${ }^{2}$, А.А. Усикова ${ }^{2}$, А.Е. Черняков ${ }^{1}$ \\ ${ }^{1}$ НТЦ микроэлектроники и субмикронных гетероструктур Российской академии наук, \\ 194021 Санкт-Петербург, Россия \\ ${ }^{2}$ Физико-технический институт им. А.Ф. Иоффре Российской академии наук, \\ 194021 Санкт-Петербург, Россия \\ ${ }^{3}$ ООО „ИофффеЛЕД“, \\ 194021 Санкт-Петербург, Россия \\ E-mail: ioffeled@mail.ru
}

(Получена 26 июля 2016 г. Принята к печати 1 августа 2016 г.)

\begin{abstract}
Проведены измерения и анализ пространственного распределения равновесного и неравновесного (в том числе люминесцентного) излучения в средневолновых ИК флип-чип фотодиодах на основе двойных гетероструктур InAsSbP/InAs ( $\lambda_{\max }=3.4$ мкм) с учетом конструктивных особенностей фотодиодов, включая отражательные свойства омических контактов. Сделана оценка увеличения оптической площади сбора фотонов за счет лучей, испытывающих многократные отражения внутри полупроводниковых чипов с различающимися геометрическими характеристиками.
\end{abstract}

DOI: $10.21883 /$ FTP.2017.02.44117.8380

\section{Введение}

Возникновению вблизи от $p-n$-перехода неравновесных электронно-дырочных пар предшествуют, как правило, процессы отражения и преломления потоков неравновесного излучения при его вхождении в полупроводник. Эти процессы могут иметь существенное влияние на величину эффективной площади сбора фотонов, и потому они являлись предметом изучения во многих публикациях, посвященных полупроводниковым фотоприемникам. Однако применительно к фотодиодам (ФД) на основе структур с гетеропереходом InAsSbP/InAs, используемым в пирометрии [1,2], газовом анализе [3] и в качестве термоэлектрических преобразователей [4], указанные исследования были крайне ограниченными и не охватывали многих аспектов указанного вопроса. Так, например, оценка отражательных свойств омических контактов к слоям InAsSbP с дырочным типом проводимости (анодов) вблизи максимума спектральной фоточувствительности проводилась лишь однажды [5], а пространственная неоднородность фоточувствительности, обусловленная вхождением фотонов в кристалл вдали от анода ограниченной площади, рассматривалась лишь для ФД, освещаемых со стороны слоя $p$-типа (англ. - Front Surface Illuminated Photodiodes (FSI PDs)). В таких ФД основной причиной неоднородности являются неравномерное растекание тока и неполный сбор фототока $[6,7]$, а не перераспределение излучения внутри полупроводникового чипа.

В данной работе проводится анализ пространственного распределения интенсивности равновесного и неравновесного излучения в ФД на основе двойных гетероструктур $P$-InAsSbP/n-InAs/ $N$-InAsSbP, выращенных на прозрачной сильнолегированной подложке $n^{+}-\operatorname{In} \operatorname{As}(100)$ и имеющих конструкцию типа флип-чип (англ. back-side illuminated (BSI) PD), и даются оценки отражательных свойств контактов и пространственной неоднородности фоточувствительности за счет потоков излучения, многократно отраженных внутри полупроводникового кристалла.

\section{Методика измерений и описание образцов}

Для создания ФД использовались двойные гетероструктуры $P$-InAsSbP $\quad(2-3$ мкм $) / n$-InAs $\quad(3-4$ мкм $) /$ $N$-InAsSbP $\quad(2-3$ мкм $) / n^{+}-\operatorname{InAs}\left(110\right.$ мкм, $\quad n^{+}=$ $\left.=2-3 \cdot 10^{18} \mathrm{~cm}^{-3}(\mathrm{Sn})(100)\right)$, аналогичные описанным нами ранее (см., например, [8]). При этом, согласно [9], имело место примерное совпадение местоположения гетерограницы и $p$-n-перехода, а также плавное изменение концентрации легирующей примеси в области объемного заряда; обе указанные особенности важны для получения низких значений темновых токов и барьерной емкости диодов [8].

Распределение в ближнем поле интенсивности электролюминесценции (ЭЛ, $\left.U_{\text {bias }}>0\right)$ и отрицательной люминесценции (ОЛ, $\left.U_{\text {bias }}<0\right)$, а также отраженного от образца излучения светодиода LED34Sr с иммерсионной линзой и максимумом излучения на длине волны 3.4 мкм [10] измерялось с помощью ИК микроскопа, оборудованного охлаждаемой до $77 \mathrm{~K}$ матрицей $128 \times 128$ из арсенида индия, имеющей максимум фоточувствительности на длине волны $\sim 3$ мкм и описанной в [11].

С помощью фотолитографии на полупроводниковой пластине выделялись/ формировались прямоугольные чипы размером $580 \times 430$ мкм, имевшие круглую ме- 
зу диаметром 35, 85, 175 или 265 мкм с круглым металлическим анодом и широким подковообразным металлическим катодом, расположенным сбоку от мезы на поверхности подложки $n^{+}$-InAs, как показано на рис. $1, a, b$. В состав анода входили, в основном, марганец и серебро, катод был изготовлен напылением композиции из последовательности слоев $\mathrm{Cr}-\mathrm{Au}-\mathrm{Ni}-\mathrm{Au}$; как и анод он был ,усилен“ при электрохимическом осаждении слоя золота толщиной 2.5 мкм. Непосредственно перед нанесением контактов методом ионно-лучевого травления в области будущего контакта удалялась часть слоя, в результате толщина слоя $P$-InAsSbP в области контактов уменьшалась на $\Delta \approx 0.25$ мкм. ФД представляли собой полученные скалыванием по плоскостям $\{110\}$ прямоугольные чипы.

Для изучения отражательных свойств анодов были также изготовлены образцы-спутники, представлявшие собой клиновидные слои $P$-InAsSbP толщиной 0-5 мкм, содержащие полосковые контакты шириной 200 мкм. При этом слой $P$-InAsSbP был приклеен к стеклянной пластинке так, что свободная от контактов поверхность $P$-InAsSbP была обращена в сторону микроскопа (см. рис. $2, a)$.

\section{Экспериментальные результаты и их обсуждение}

На рис. 1, $c$ приведено ИК изображение несмонтированного чипа ФД, находящегося на поверхности зеркала с алюминиевым покрытием (коэффициент отражения $R \geq 0.9$ ). На рис. $1, c$ и на всех последующих рисунках использована стандартная гамма раскраски: белому цвету соответствует большая интенсивность излучения, темному - малая. На изображениях со стороны эпитаксиальных слоев/контактов в ИК (рис. 1,c) и в видимом (рис. $1, b$ ) диапазонах спектра хорошо видны более яркие по отношению к другим областям прямоугольная „рамка“, соответствующая вытравленным по краям чипа канавкам разделения, и „кольцо“ вокруг мезы. Эти краевые области/,склоны“ проявляются из-за того, что наклонные области эффективно перенаправляют рассеянное излучение из областей вне объекта измерения на входное отверстие микроскопа/фотоаппарата. По этой же причине зеркальные (или близкие к зеркальным) поверхности, перпендикулярные направлению измерения, выглядят темными, поскольку нормально падающих лучей в описываемом эксперименте практически нет. Для обоих микроскопов объектив не является источником подсвечивающего излучения: для оптического микроскопа подсветка организована диффузно рассеянным светом, исходящим с боковых направлений, а для ИК микроскопа его объектив является „холодным“ (т.е. слабо излучающим объектом), и поэтому основная часть регистрируемого излучения формируется за счет собственного теплового излучения полупроводника и излучения, отраженного от склонов.

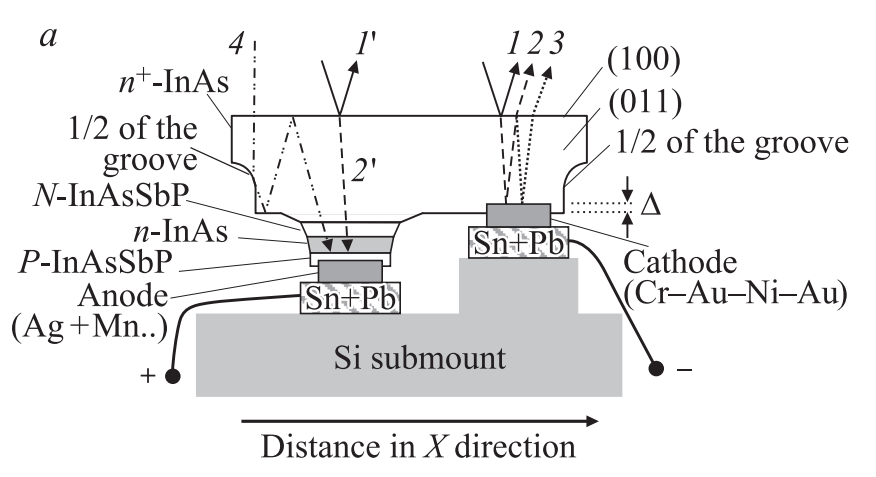

$b$
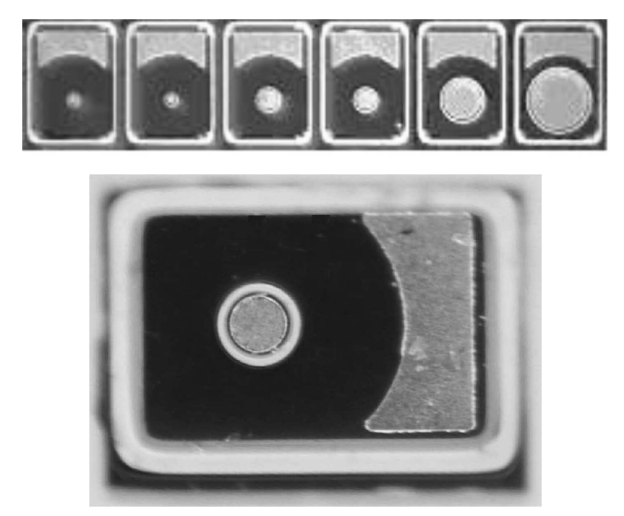

$c$

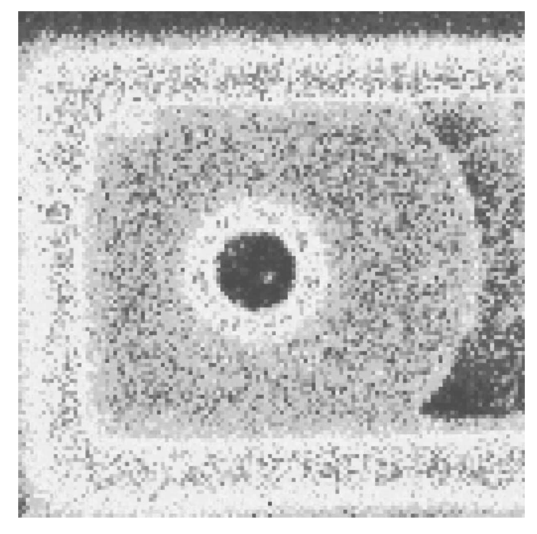

$d$

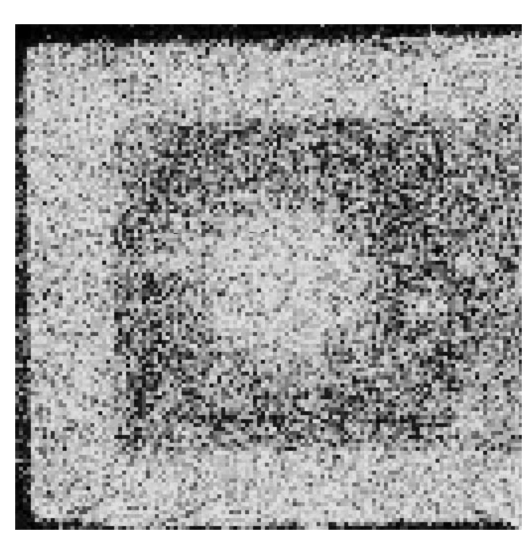

Рис. 1. Схема сечения $(a)$, фотография однотипных чипов ФД с разными диаметрами мезы $(b)$ и ИК изображения чипа с мезой диаметром 85 мкм со стороны контактов(слоев) (c) и подложки $(d)$ в условиях термодинамического равновесия $(U=0, T=300 \mathrm{~K})$. Лучи в области анода: $1^{\prime}, 2^{\prime}$, лучи в области катода: $1,2,3$. Для наглядности на фотографиях использован разный масштаб. 
Как видно из рис. $1, b$, с контраст изображения для обоих контактов существенно выше для ИК области, чем для видимого диапазона спектра. Вероятнее всего, это обусловлено тем, что характерный размер шероховатостей металлической поверхности $(\delta)$ меньше длины волны при ИК измерениях $(\delta<\lambda=3$ мкм); для видимого диапазона это условие не выполняется (т.е. $\delta>\lambda=0.4-0.8$ мкм), и контакт диффузно рассеивает попадающее на него с боков видимое излучение. При этом можно отметить, что интенсивность ИК излучения (на рис. 1 это - цвет), отраженного от зеркала (см. горизонтальную область в верхней части рис. 1,c), практически совпадает с интенсивностью излучения от круглого анода, что позволяет сделать вывод о высоком коэффициенте отражения контакта (точнее - его поверхности, не контактирующей с полупроводником): $R>0.9$.

При измерении со стороны подложки (см. рис. $1, d$ ) структура ИК изображения видоизменяется, а именно: область мезы проявляется в данных условиях, как область с повышенной излучательной/поглощательной способностью. Эти данные вполне закономерны, если принять во внимание, что конструкция ФД типа BSI предполагает наличие значительной прозрачности у подложки и сильное поглощение излучения активным слоем; максимум спектра чувствительности при этом имеет место при $\lambda=3.4$ мкм [8]. На самом деле подложка прозрачна лишь частично, поскольку на ИК изображении она (см. область, окружающую мезу) более яркая, чем зеркало, т. е. в ней присутствует заметное поглощение на длине волны 3 мкм. В этой связи оценка коэффициента отражения от границы раздела $P$-InAsSbP/анод была проведена с помощью измерений образцов (слоев) без подложки, описанных далее.

На рис. 2 приведены схема $(a)$, фотография $(b)$ и ИК изображение $(c)$ одного из образцов-спутников при температуре $88^{\circ} \mathrm{C}$. Как видно из рис. $2, c$, контактные полоски имеют наименьшую интенсивность излучения, помимо этого разнотолщинные области образца (клина) характеризуются „волнистой“, т.е. осцилляционной структурой ИК изображения, возникающей, очевидно, вследствие интерференции тепловых лучей. В области с большой толщиной слоя (справа на рис. 2,c) осцилляции пропадают, очевидно, вследствие сильного поглощения излучения в $P$-InAsSbP. Нетрудно заметить, что фазы осцилляций при примерно одинаковой толщине слоя были противоположны для смежных областей над контактом (области темных горизонтальных по отношению к чертежу полосок) и над свободными от контакта областями (области более светлых полосок). Это продемонстрировано также и на рис. $2, d$, где представлено распределение интенсивности излучения вдоль полосок контакта для двух близко расположенных областей образца, а именно, для области, где имеет место отражение от границ металл/полупроводник $(Y=1300$ мкм, область $M$ на рис. $2, b, c)$ и области сопряжения полупроводник/клей (область $F$ с $Y=1129$ мкм там же). Локальные экстремумы двух зависимостей в своем большинстве сдвинуты $a$

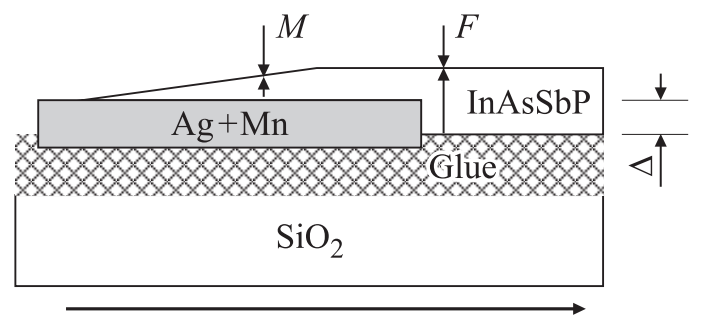

Distance in $X$ direction

$b$

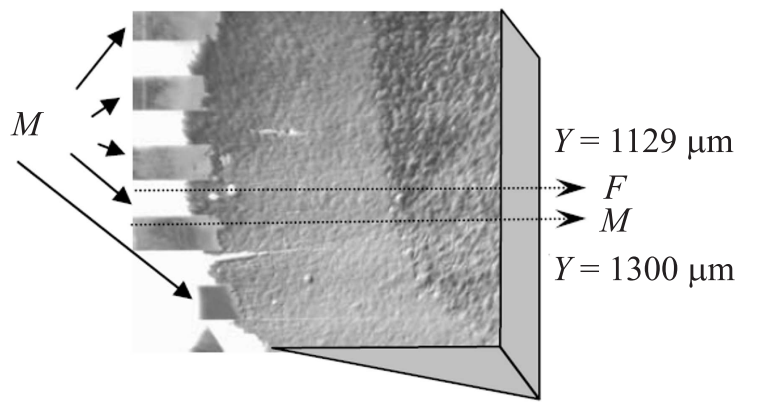

$c$
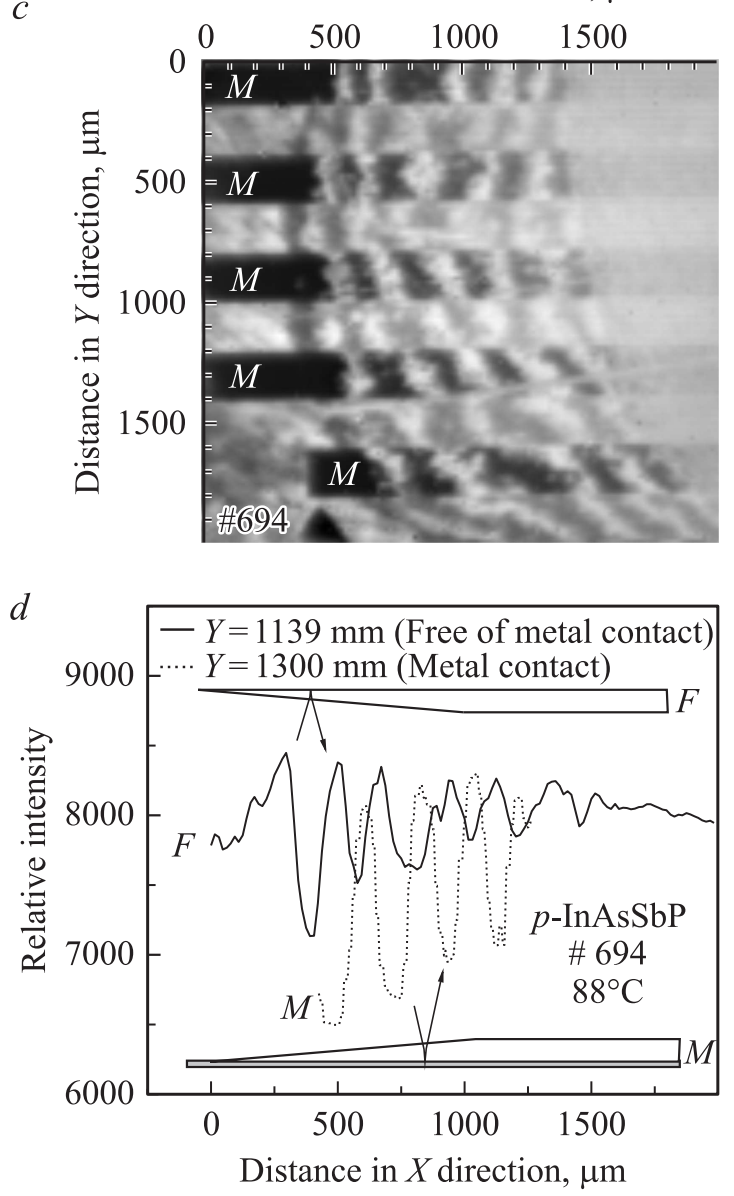

Рис. 2. Схема $(a)$, фотография $(b)$ и ИК изображение $(c)$ со стороны слоя клиновидного образца и распределение интенсивности излучения $(d)$ вдоль двух выделенных направлений: над металлическим контактом (область $M$, штриховая линия) и над слоем, где контакта нет (область $F$, сплошная линия). На фотографии образца $(b)$ для наглядности дорисованы две боковые грани. 


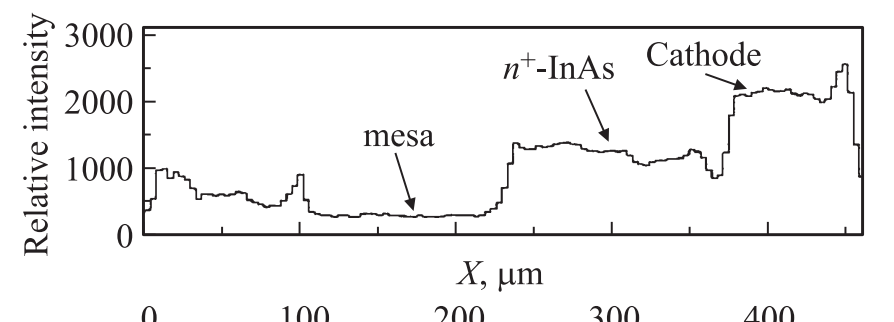

InAs DH PD \#159

$300 \mathrm{~K}, I_{\mathrm{LED}}=32 \mathrm{~mA}$
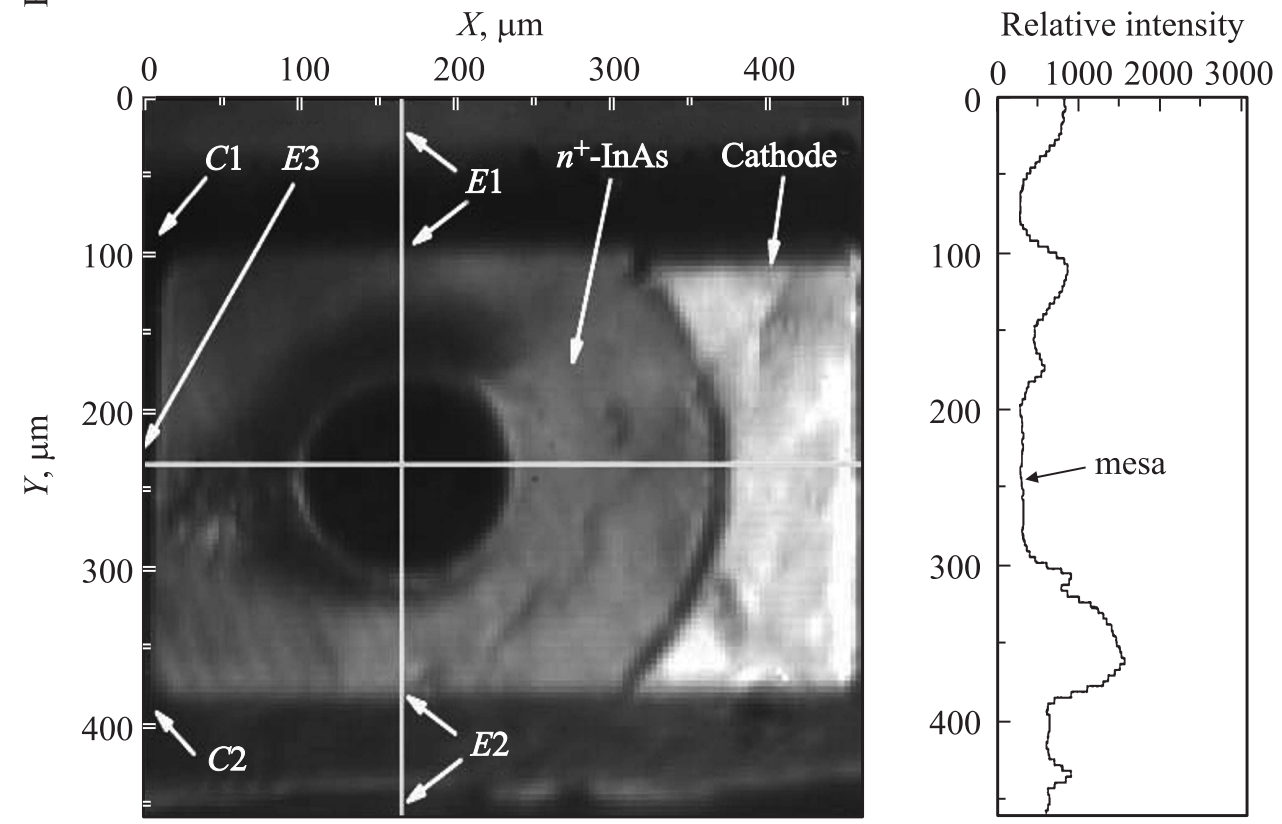

Рис. 3. ИК изображение ФД, полученное при подсветке внешним источником со стороны $n^{+}$-InAs и соответствующее ему распределение интенсивности излучения в „вертикальном“ ( $Y$, правая панель) и „горизонтальном“ $(X$, верхняя панель) сечениях, показанных сплошными светлыми линиями. Буквами „Е“ обозначены края, а буквами „ $C^{“}$ - углы чипа.

друг относительно друга по фазе (на $\pi$ ), что объясняется тем, что при отражении излучения от металла фаза световой волны изменяется на $\pi$, в то время как при отражении от границы полупроводник/непроводящий клей она сохраняется ${ }^{1}$. Вероятно, по этой же причине интерференция волн слоя без металла начинается при меньших значениях толщины слоя $P$-InAsSbP, чем для начала появления интерференционных полос над слоем с металлом.

Для количественного описания осцилляций излучательной способности при интерференции в полупроводниковой пластине можно воспользоваться аналитическим выражением для разности локальных значений минимальной и максимальной интенсивности собственного излучения плоскопараллельной полупроводниковой пластины $\Delta I=I_{\max }-I_{\min }$, приведенным в работе [12]: $\Delta I=\frac{4 \eta R(1-R)(1-\eta)}{(1-\eta R)^{2}(1+\eta R)}$, где $R-$ средний коэффициент отражения, $\eta$ - степень ослабления теплового излучения при однократном прохождении через пластинуㄹ․ При

\footnotetext{
${ }^{1}$ Небольшое различие в толщине $\Delta=0.25$ мкм не является решающим при сдвиге фазы, поскольку оно мало по сравнению с длиной волны излучения.

2 Линейность фотоответа в фотоприемной матрице была проверена и подтверждена при измерениях интенсивности отраженных лучей при различных накачивающих токах в калиброванном (т.е. с известной ватт-амперной характеристикой) светодиоде LED34Sr.
}

наилучшем соответствии данных на рис. 2 приведенному выше соотношению коэффициент отражения от контакта, по крайней мере, в 2 раза выше, чем для области без него. При этом нижняя оценка коэффициента отражения от границы $P$-InAsSbP/Ag + Mn составляла 0.3 .

При использовании внешней подсветки ИК изображения чипа „инвертируются“: слабо светящиеся области (при равновесии) оказываются наиболее яркими (при подсветке) (см., например, [13]). Это же демонстрируют и данные на рис. 3, где приведено ИК изображение смонтированного на носитель чипа ФД в условиях его засветки излучением СД, направленным почти вертикально к поверхности $n^{+}-\operatorname{InAs}{ }^{3}$; там же представлено распределение интенсивности излучения с длиной волны вблизи 3 мкм в двух выделенных сечениях, параллельных граням чипа. Из рис. 3 видно, что наибольшая яркость изображения чипа соответствует области катода, а область наименьшей яркости совпадает по форме с круглой мезой. Для оценки коэффициента отражения $R_{c}$ от границы раздела (ГР) катод/ $n^{+}$-InAs была использована простая модель, предполагающая равномерное распределение интенсивности падающего на чип излучения для близко расположенных друг от друга областей и

\footnotetext{
${ }^{3}$ На рис. 1 для наглядности показано косое падение лучей на поверхность ФД, в реальном эксперименте основная часть лучей от СД падала нормально к поверхности $n^{+}$-InAs.
} 
формирование отраженного от чипа потока излучения в области над мезой $\left(I_{m}\right)$ лишь за счет отражения излучения от поверхности подложки (т.е. границы раздела $n^{+}$-InAs/воздух - обозначена цифрами 001, луч, обозначенный цифрой $l^{\prime}$ на рис. $\left.1, a\right)$ с коэффициентом $R=\frac{\left(n_{1}-n_{2}\right)^{2}}{\left(n_{1}+n_{2}\right)^{2}}, n_{1}=1, n_{2}=3.52^{4}$. В рамках этого допущения суммарная интенсивность вышедшего из кристалла излучения, сформированного лишь с участием отражения от нижней грани чипа (см. лучи, обозначенные цифрами 2, 3 на рис. 1, $a$ ), равна интенсивности регистрируемого излучения $\left(I_{s, c}\right)$ за вычетом интенсивности излучения в области мезы (анода) $I_{m}$, где индексы $S$ и $C$ соответствуют данным для интенсивности отраженного излучения от области чипа вне контактов и от области с катодом соответственно. Подгонка расчетных значений, наилучшим образом соответствующих эксперименту, для которого $\left(I_{c}-I_{m}\right) /\left(I_{s}-I_{m}\right)=1.9$ проводилась при значении $R_{a}=0.6$, практически совпадающим с нашими более ранними оценками коэффициента отражения от ГР контакт/полупроводник в диодах с активным слоем из InGaAsSb [13] и InAsSbP [14] с той же последовательностью металлов. Вывод о более низком, чем от зеркала, значении коэффициента отражения качественно согласуется с тем, что на ,равновесном“ ИК изображении, полученном со стороны подложки (рис. $1, d$ ), область катода более яркая, чем область без контактов (подложка выглядит менее яркой из-за зеркала с высоким коэффициентом отражения, расположенного за(под) ней).

Вполне очевидно, что отражательные свойства контактов, а также малые потери излучения на рабочей длине волны создают возможность для перераспределения неравновесного потока излучения в ФД благодаря многократному его отражению внутри полупроводникового чипа. Особую роль при этом играют края чипа, как это следует из приведенного выше анализа „равновесных“ ИК изображений. Действительно, как и в ФД типа BSI на основе InGaAsSb/GaSb [15], перераспределение ЭЛ излучения формировало яркие области вблизи краев чипа, а также в его угловых зонах (см. рис. 4, а также рис. 3 , где указанные зоны обозначены буквами $E$ (edge) и $C$ (corner), и рис. $1, a$, на котором один из вариантов формирования подобных областей обозначен крайней левой стрелкой и цифрой 4). Наибольшая интенсивность краевого излучения, как видно из рис. 4 , имела место на направлениях, пересекающих мезу перпендикулярно граням чипа. В соответствии с фундаментальным принципом обратимости хода лучей в оптических системах можно ожидать, что и входящее в полупроводниковый кристалл неравновесное излучение будет также иметь указанные выше особенности пространственного распределения. Действительно, при смещении $p-n$-перехода в

\footnotetext{
${ }^{4}$ Использованное значение коэффициента отражения от поверхности $n^{+}$-InAs не вполне соответствует всей совокупности экспериментальных данных на рис. 3, в частности, степень отражения от области над мезой оказывается заниженной по сравнению с ожиданиями. Одной из причин может быть непараллельность верхней и нижней граней чипа, однако истинные причины указанного расхождения будут выявлены в ходе дальнейших исследований.
}

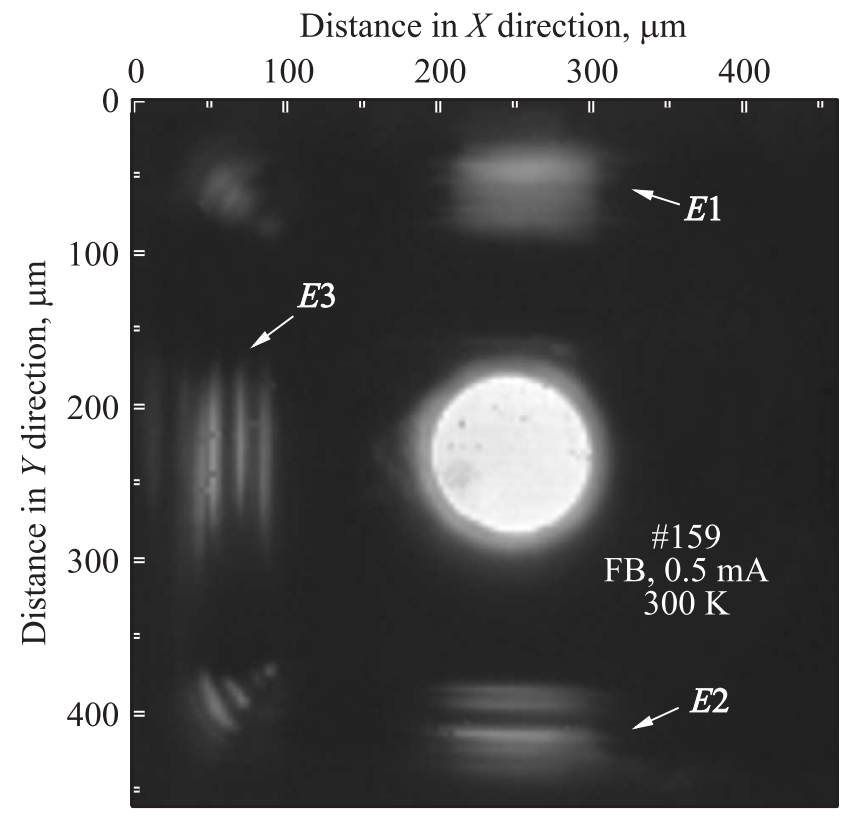

Рис. 4. ИК изображение чипа ФД при протекании через него прямого тока $0.5 \mathrm{MA}$.

обратном направлении в распределении интенсивности излучения помимо основной области с пониженной излучательной способностью, обусловленной инициацией отрицательной люминесценции (ОЛ) в области круглой мезы, наблюдались также области с пониженной излучательной способностью на краях чипа, причем их пространственное расположение закономерно коррелировало с местоположением пиков ЭЛ (см. рис. 5). Полученные данные свидетельствуют о том, что края чипа вносят ощутимый вклад в поглощаемый вблизи от $p-n$-перехода поток излучения. Следствием этого является, в частности, азимутальная неоднородность фоточувствительности, что важно учитывать, например, при использовании вытянутых диафрагм (или щелей), ограничивающих падающий поток излучения до размеров, близких к поперечным размерам мезы.

Разумеется, что влияние краев чипа необходимо учитывать при определении параметров фоточувствительности в тех случаях, когда ширина падающего потока больше поперечных размеров мезы. Влияние геометрических характеристик ФД на фоточувствительность отражено на рис. 6 , где представлены значения токовой чувствительности $\left(S_{I}\right)$ в зависимости от диаметра мезы $(d)$ в ФД однотипной конструкции (см. рис. 1) при засветке всего чипа целиком. При расчете $S_{I}$ за оптическую площадь $\left(A_{\text {opt }}\right)$ принималась площадь мезы $\left(A_{\text {mesa }}\right)$ или площадь всего чипа $\left(A_{\text {chip }}\right)$. Помимо этого производились также измерения и на образцах, в которых дополнительным скалыванием граней поперечный размер $(L)$ и, соответственно, площадь чипа $\left(A_{\text {sample }}\right)$ уменьшалась до минимально возможных размеров, т.е. при максимальном приближении граней к краям круглой мезы $(L \approx d)$. 

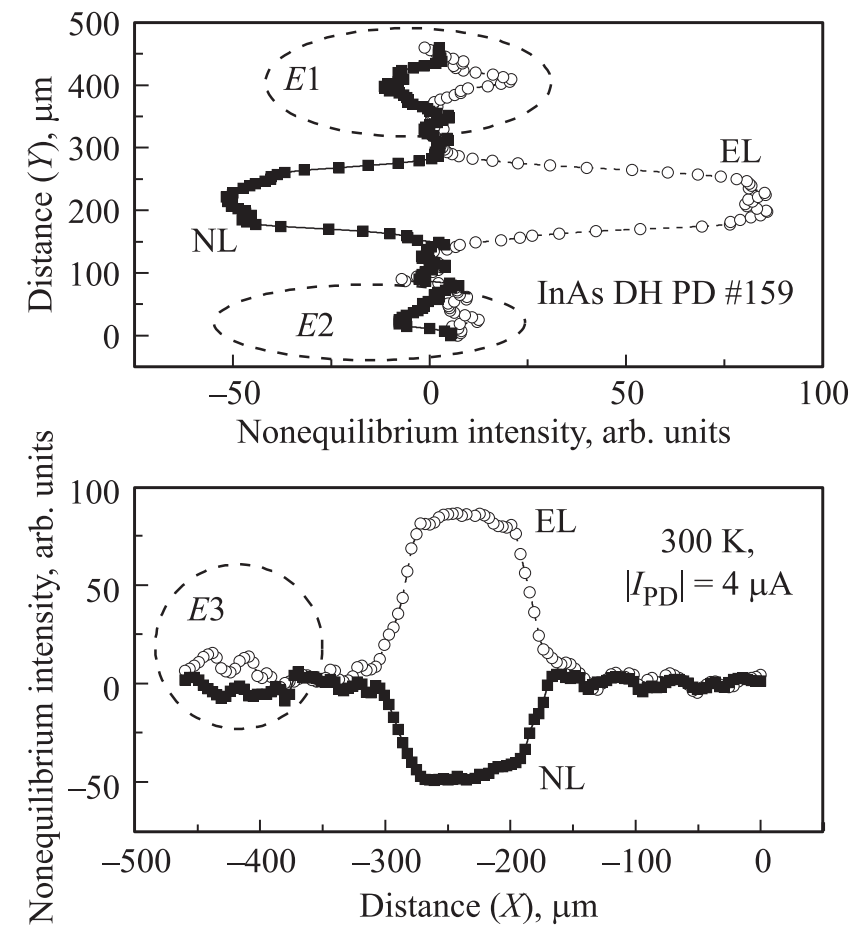

Рис. 5. Распределение интенсивности неравновесного излучения (ЭЛ (EL, $U>0)$ и ОЛ $(\mathrm{NL}), U<0)$ вдоль вертикального (вверху) и горизонтального сечений (внизу), проходящих через центр мезы при токе через диод 4 мкА. Нулевой уровень интенсивности соответствует равновесному состоянию диода $(U=0, I=0)$. Области, обозначенные как $E 1, E 2$ и $E 3$, а также направления осей соответствуют таковым на рис. 3, 4.

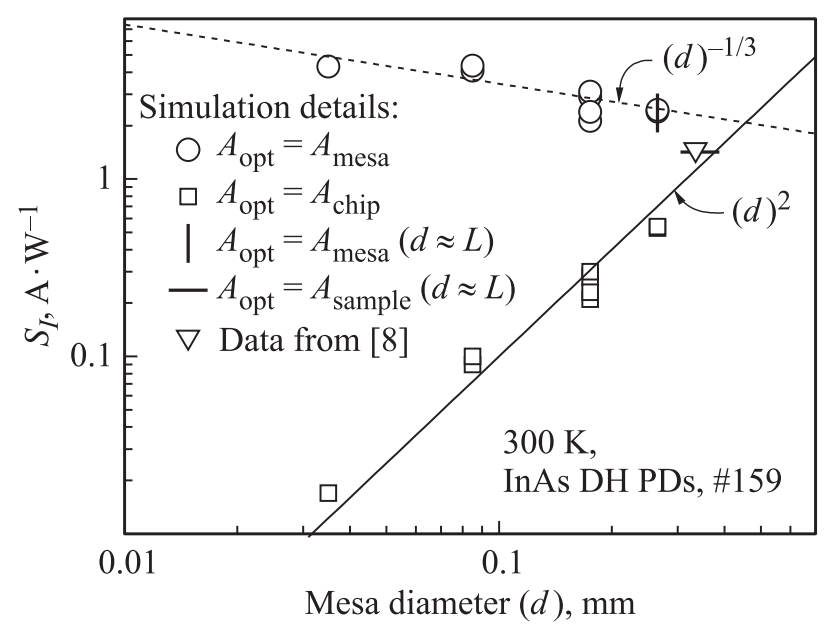

Рис. 6. Зависимость токовой фоточувствительности $\left(S_{I}\right)$ от диаметра мезы $(d)$ для ФД с однотипными чипами $(\square$, o) и для дополнительно сколотых образцов ФД $(\boldsymbol{m}, \diamond)$ при засветке всего чипа целиком. Сплошной линией представлена зависимость $S_{I} \sim(d)^{2}$, а штриховой $-S_{I} \sim(d)^{-1 / 3}$. Детали расчета - на графике.

Нетрудно видеть, что в условиях данных экспериментов значение $S_{I}$ для стандартных чипов существенным образом зависела и от диаметра мезы, и от способа расчета (выбора значения оптической площади), причем расчет в предположении о равенстве $A_{\text {opt }}$ и $A_{\text {mesa }}$ для всех диаметров мез приводил к значению квантовой эффективности, превышающей 0.7. Указанное завышенное значение, искусственно обусловленное условиями эксперимента, должно быть проигнорировано при оценке эффективности ФД, поскольку при использовании более обоснованных условий измерений, например, образцов с большим диаметром мезы и(или) диафрагм, установленных на пути лучей, внешняя квантовая эффективность не превышает 0.7 [8,16].

Очевидно, что зависимость фоточувствительности от размера мезы имеет сложный характер, поскольку при изменении диаметра изменяется соотношение между высотой мезы и ее поперечным размером, т.е. изменяются параметры „внутреннего концентратора излучения“, сформированного наклонными стенками мезы [17], а также изменятся площадь и условия сбора излучения от областей вне концентратора. Помимо этого нельзя исключать возможность влияния на $S_{I}$ токов утечек по поверхности ФД с малыми размерами мезы (в нашем случае - это ФД с диаметром мезы, равным 35 мкм).

\section{Заключение}

Таким образом, показано, что в ФД на основе InAsSbP/InAs с конструкцией типа флип-чип и отражающими контактами имеется существенное перераспределение неравновесного излучения, одним из следствий которого является появление дополнительных максимумов фоточувствительности, расположенных вблизи краев чипа. Перераспределение излучения имеет следствием также и эффективное увеличение фоточувствительности (до 3-х раз) при засветке ФД с большим отношением площадей мезы и чипа. Указанные особенности необходимо учитывать при конструировании, прогнозировании и анализе реальных параметров эффективности фотопреобразования в активной области ФД.

Авторы выражают благодарность А.С. Петрову (ОАО „ЦНИИ Электрон“) за полезные обсуждения, а также Т.Б. Поповой, П.Н. Брункову (ЦКП „Материаловедение и диагностика в передовых технологиях“) за помощь в проведении измерений. Исследования ближнего поля собственной эмиссии ФД и отраженного излучения были осуществлены в ЦКП „Элементная база радиофотоники и наноэлектроники: технология, диагностика, метрология“.

Работа, выполненная в ООО „ИоффеЛЕД“, поддержана проектом ФЦП „Разработка технологии получения полупроводниковых фоточувствительных материалов для матричных инфракрасных фотоприемников и тепловизоров“ (код контракта 14.576.21.0057, ID: RFMEFI57614X0057). 


\section{Список литературы}

[1] S.E. Aleksandrov, G.A. Gavrilov, A.A. Kapralov, G.Yu. Sotnikova. Physics Procedia, 73, 177 (2015).

[2] X. Zhou, X. Meng, A.B. Krysa, J.R. Willmott, J.S. Ng, Ch.H. Tan, IEEE Sens. J. 15 (10), 5555 (2015).

[3] А.А. Кузнецов, О.Б. Балашов, Е.В. Васильев, С.А. Логинов, А.И. Луговской, Е.Я. Черняк, Приборы и системы. Управление контроль, диагностика, № 6, 55 (2003).

[4] A.Krier, M.Yin, A.R.J. Marshall, S.E. Krier. Journal of ELECTRONIC MATERIALS DOI: 10.1007/s11664-016-4373-0 DOI:10.1007/s11664-016-4373-0 (http://paperity.org/p/75304169/low-bandgap-inas- based-thermophotovoltaic-cells-for-heat-electricity-conversion) (2016).

[5] B. Matveev., N. Zotova, N. Il'inskaya, S. Karandashev, M. Remennyi, N. Stus'. Phys. St. sol. (c) 2 (2), 927 (2005).

[6] Indium Arsenide Detectors, Judson Technologies LLC, www.judsontechnologies.com

[7] B.A. Matveev, A.V. Ankudinov, N.V. Zotova, S.A. Karandashev, T.V. L'vova, M.A. Remennyy, A.Yu. Rybal'chenko, N.M. Stus'. Proc. SPIE, 7597, 75970G (2010).

[8] P.N. Brunkov, N.D. Il'inskaya, S.A. Karandashev, N.G. Karpukhina, A.A. Lavrov, B.A. Matveev, M.A. Remennyi, N.M. Stus', A.A. Usikova. Infrared Physics and Technology, 76, 542 (2016), DOI information: 10.1016/j.infrared.2016.04.002.

[9] М.А. Ременный, П.Н.Брунков, Н.Д. Ильинская, С.А. Карандашев, Н.Г.Карпухина, А.А.Лавров, Б.А. Матвеев, Н.М. Стусь, А.А. Усикова. Тр. 24-ой Межд. науч.-технич., конференции по фотоэлектронике и приборам ночного видения, 24-27 мая 2016 года, Москва, стр. 111 (2016).

[10] www.ioffeled.com

[11] В.М. Базовкин, А.А. Гузев, А.П. Ковчавцев, Г.Л. Курышев, А.С. Ларшин, В.Г. Половинкин. Прикладная Физика, № 2, 97 (2005).

[12] К.Ю. Гуга, А.Г. Коллюх, А.И. Липтуга, В.А. Мороженко, В.И. Пипа. ФТП, 38 (5), 524(2004).

[13] B.A. Matveev, Yu.M. Zadiranov, A.L. Zakgeim, N.V. Zotova, N.D. Il'inskaya, S.A. Karandashev, M.A. Remennyy, N.M. Stus', A.A. Usikova, O.A. Usov, A.E. Cherniakov. Proc. of SPIE, 7223, 72231B-1-7 (2009), doi: 10.1117/12.808130

[14] А.Л. Закгейм, Н.В. Зотова, Н.Д. Ильинская, С.А. Карандашев, Б.А. Матвеев, М.А. Ременный, Н.М. Стусь, А.А. Усикова, А.Е. Черняков. Прикладная Физика, № 6, 143 (2008).

[15] С.А. Карандашев, Б.А. Матвеев, М.А. Ременный, А.А. Шленский, Л.С. Лунин, В.И. Ратушный, А.В. Корюк, Н.Г. Тараканова. ФТП, 41 (11), 1389 (2007).

[16] P.N. Brunkov, N.D. Il'inskaya, S.A. Karandashev, A.A. Lavrov, B.A. Matveev, M.A. Remennyi, N.M. Stus', A.A. Usikova. Infrared Phys. Technol., 73, 232 (2015).

[17] А.Л. Закгейм, Н.В. Зотова, Н.Д. Ильинская, С.А. Карандашев, Б.А. Матвеев, М.А. Ременный, Н.М. Стусь, А.Е. Черняков. ФТП, 43 (3), 412 (2009).

Редактор Г.А. Оганесян

\section{Radiation spatial redistribution in flip-chip InAsSbP/InAs DH photodiodes}

\author{
A.L. Zakgeim ${ }^{1}$, N.D. Il'inskaya ${ }^{2}$, S.A. Karandashev², \\ A.A. Lavrov ${ }^{3}$, B.A. Matveev ${ }^{2}$, M.A. Remennyy ${ }^{2}$, \\ N.M. Stus'2, A.A. Usikova ${ }^{2}$, A.E. Cherniakov ${ }^{1}$ \\ ${ }^{1}$ Submicron Heterostructures \\ for Microelectronics Research \& Engineering Center, \\ 194021 St. Petersburg, Russia \\ 2 loffe Institute, \\ 194021 St. Petersburg, Russia \\ ${ }^{3}$ loffeLED, Ltd., \\ 194021 St. Petersburg, Russia
}

Abstract Reflection and redistribution of equilibrium and nonequilibrium radiation including luminescence in InAsSbP/InAs $\left(\lambda_{\max }=3.4 \mu \mathrm{m}\right)$ DH flip-chip photodiodes have been measured and analyzed. Optical area enhancement due to multiple internal reflection in photodiodes with different geometrical characteristics has been evaluated. 